\title{
DA SOBERANIA DO INÚTIL
}

Antônio Teixeira*

RESUMO O autor demonstra, de início, a importância do aspecto qualitativo da percepção eliminado pelo saber científico no discurso poético. A seguir, salienta que a percepção dos elementos da natureza na forma de utensílios, através do trabalho, introduziu uma relação de exterioridade que interrompeu a forma original de participação subjetiva. Conclui discutindo, nos termos de uma relação de participação íntima, não instrumental, do sujeito para com o objeto, a noção freudiana de viscosidade da libido.

Palavras-chave Inútil, Trabalho, Viscosidade da Libido

ABSTRACT From the beginning the author demonstrates the importance in poetic discourse of qualitative aspects of perception eliminated by scientific knowledge. The author then shows that the perception of nature as utensils through work has introduced a relationship of externality that has interrupted original subjective participation. He concludes by discussing in terms of an intimate relationship, not of an instrumental participation involving the subject and the object, the Freudian notion of libido's viscosity.

Keywords Useless, Work, Libido’s Viscosity

* Professor do Departamento de Psicologia da Universidade Federal de Minas Gerais. Este escrito, até o momento inédito, é a versão modificada de um trabalho apresentado a convite de Vladimir Safatle, durante o Primeiro Encontro Nacional de Psicanálise e Filosofia, ocorrido em novembro 2004 no Departamento de Filosofia da USP. Artigo recebido em novembro de 2004 e aprovado em junho de 2005. amrteixeira@uol.com.br

KRITERION, Belo Horizonte, $n^{0}$ 111, Jun/2005, p. 91-103 
Aqui jaz um grande poeta.

Nada deixou escrito.

Este silêncio, acredito,

são suas obras completas

(Paulo Leminski)

A François Regnault

Ao escrever, em 1791, seu tratado intitulado Doutrina das Cores (Farbenlehre), Goethe se insurge claramente contra a ótica mecanicista herdada de Newton. Goethe ali discorda do modelo científico que opera através da dissolução das qualidades perceptivas da luz, com vistas a apreender as suas variações cromáticas a partir do cálculo matemático do comprimento de onda. O que lhe importa, principalmente, é restabelecer a percepção da cor em função justamente do aspecto qualitativo eliminado pelo saber científico, restaurando o valor de sua interpretação subjetiva. Não é, a seu entender, com um conjunto de prismas e cálculos que se entende a cor, cuja natureza se dá a conhecer com a participação do olho, que é um órgão vivo. O conhecimento da natureza das cores não é o conhecimento matemático de um olhar que dela se separa, mede e calcula; o olhar que conhece a cor é, antes de tudo, um olhar que por ela se deixa impressionar e por ela se fascina.

Verifica-se claramente, nessa perspectiva romântica do conhecimento, que a reflexão de Goethe, a seu modo, inaugura - à qual a fenomenologia hermenêutica não tardaria a dar o nome de conhecimento por empatia (Einfühlung) - o desejo de se restaurar, por assim dizer, uma espécie de participação libidinal do sujeito com relação ao objeto a ser conhecido. Tratase de um modo de apreensão do objeto que se pode contrapor ao que seria a percepção predominantemente instrumental dos elementos do mundo, cuja natureza é considerada somente no que tange ao uso que dele se pode fazer em função de um cálculo previsto. Haveria, nesse sentido, uma tentativa de fundar o conhecimento da natureza numa dimensão de imanência e participação anterior à separação que dela se instalou com a sua percepção instrumental.

É aliás um fato, amplamente comentado por Bataille, que a percepção dos elementos da natureza, na forma do utensílio, veio a ser a forma pela qual o homem introduziu no mundo, através do trabalho, uma relação de exterioridade que interrompeu a sua forma original de participação subjetiva. O utensílio, na visão de Bataille, é a forma nascente do objeto-coisa em sua exterioridade 
como não $\mathrm{Eu}^{1}$. Ao passo que o elemento do qual o sujeito participa não lhe é originariamente subordinado, como a luz a fascinar o olhar de Goethe (ou como a visão de Charlotte a encantar o olhar do jovem Werther), o objeto utensílio é o elemento do qual eu me separo, no sentido em que dele paro de participar para submetê-lo a um fim que lhe é exterior. Sua objetividade depende da entrada de uma percepção para a qual ele deixa de ter valor em si mesmo, passando a ser apreendido somente a partir de um sistema de relações com vistas a um resultado determinado que o ultrapassa. Essa objetividade que a técnica moderna teria conduzido, aos olhos de Heidegger, a seu mais extremo limite, consiste na interpelação do ente a partir de uma montagem (Gestell) concebida para dirigir sua apreensão na forma calculada do uso disponível ${ }^{2}$.

Acontece porém, acrescenta Bataille, que se, por um lado, o elemento do mundo, convertido em instrumento, passa a ser considerado em relação a um fim exterior a ele, em sua forma utilitária, por outro lado o próprio fim a se alcançar pelo instrumento acaba sendo colocado, nessa mesma perspectiva, como meio para outra meta que, por sua vez, também o transcende, sem que se possa determinar qual seria a finalidade última desse circuito. Assim o pau, que perfura o solo, deve servir para assegurar o crescimento da planta que, por sua vez, é cultivada para manter a vida de quem procura o pau para perfurar o solo, e daí por diante, indefinidamente ${ }^{3}$. O utensílio submete, desse modo, o próprio homem que dele se serve à servidão desse circuito contínuo, alienandoo também, por sua vez, como um meio para algo que lhe é exterior. Apenas a absurdidade desse reenvio infinito justifica, prossegue Bataille, "a absurdidade equivalente de um verdadeiro fim", a saber, de algo que, finalmente, para nada serviria. O que o verdadeiro fim reintroduz é o ser contínuo da participação inútil "perdido no mundo como a água o é na água", onde os elementos se encontram imersos indistintamente na dimensão do gasto improdutivo. Somente nesse mundo em que os seres são indistintamente supérfluos se pode conceber a dimensão soberana daquilo que para nada serve, que existe como fim em si, e não em vista de outra coisa ${ }^{4}$.

Totalmente diverso, portanto, do elemento imerso nesse mundo imanente, é o objeto dotado de sentido instrumental que rompe com essa continuidade indistinta. O objeto-coisa, desprovido de finalidade intrínseca, é radicalmente exterior ao sujeito que conhece o seu funcionamento, tanto mais que sua

1 BATAILLE, G. Théorie de la religion. In: CEuvres complètes, VII. Paris: Gallimard, 1976, p. 297.

2 HEIDEGGER, M. La question de la technique. In: Essais et conférences. Paris: Gallimard, 1958, p. 32; e HEIDEGGER. Science et méditation, op.cit, p. 68.

3 BATAILLE. Théorie de la religion, p. 298.

4 Idem. 
apreensão cognitiva depende precisamente da exterioridade que o separa do sujeito $^{5}$. O que se percebe, nessa humanização instrumental do mundo introduzida pelo trabalho - a qual se atesta pela presença de utensílios nos mais remotos lugares em que uma comunidade humana se formou - é a captura dos seus elementos numa montagem que define a própria esfera das relações coordenadas pelas leis da linguagem. Assim como o objeto encadeado na montagem utilitária deixa de ser considerado por si mesmo para ser visto somente como uma peça em relação ao sistema de uso em que ele se encadeia ${ }^{6}$, na montagem simbólica estruturada pela linguagem cada elemento significante encontra seu valor determinado para além de si mesmo, conforme as relações que entretém com os demais elementos do sistema que ali se compõe.

A introdução do trabalho vem interromper, destarte, a intimidade do sujeito para com o mundo, ao substituir o livre desencadeamento do desejo pelo encadeamento racional da previsão. A verdade do instante não mais importa, a partir do momento em que tudo converge para o cálculo que essa montagem provê como resultado final de suas operações ${ }^{7}$. É, portanto, nesse mundo humanizado pelo trabalho e estruturado como um sistema de linguagem, que Bataille nos convoca a considerar o fenômeno ritual do sacrifício, assim como o escândalo que sua prática suscita. Mas o que lhe importa não é, propriamente falando, captar qual seria o verdadeiro sentido do sacrifício, conforme tentaram os antropólogos que o antecederam; no seu entender, o que o sacrifício coloca em suspenso é justamente a dimensão do sentido regulado pelas leis da linguagem.

É portanto exato afirmar, embora isso possa soar como um mero quiasmo retórico, que o sentido do sacrifício consiste no sacrifício do sentido ${ }^{8}$. Por suspeitar que a lógica do sentido seja uma lógica derivada do interesse servil, Bataille propõe que se conceba a experiência do sacrifício, fora da regência do sentido, no horizonte da soberania inútil, a ser entendida como dimensão que excede a todo interesse de uso. O sacrifício é somente soberano na medida em que o discurso significativo não o informa. Se não faz, por conseguinte, sentido perguntar qual seria a utilidade social do sacrifício, na visão de Bataille,

5 BATAILLE. Théorie de la religion, p. 298.

6 A propósito das conseqüências propriamente modernas do que veio a ser a máquina utilitária de J. Bentham, Cf. J.-A. MILLER. Le despotisme de l'utile: la machine panoptique de J. Bentham. In: Barca!: L'Utile et la jouissance, S/E, Paris, 1993, n. 1, p. 154 (para a referência acima) e passim.

7 BATAILLE. La part maudite. In: CEuvres Complètes, p. 62.

8 Essa formulação não é de minha autoria. Ela nada mais é do que a transformação de uma outra, proposta por B. Baas, o qual afirma, ao conjugar Bataille com Kant, que o esquema do sacrifício é justamente o sacrifício do esquema, ou seja, "o sacrifício de um objeto de experiência (no caso, o objeto-coisa) ao estatuto do objeto êxtimo". Cf. BAAS, B. O desejo puro. Rio de Janeiro: Revinter, 2001, p. 105. 
é porque o sacrifício vem romper precisamente com o circuito da utilidade e do sentido. A utilidade do sacrifício é antes o sacrifício da utilidade, caso nos permitam mais uma outra inversão, posto que a sua função — se é que se pode legitimamente atribuir uma função ao sacrifício — é restituir ao mundo sagrado da participação íntima aquilo que o uso servil degradou ${ }^{9}$. O sacrifício se opõe à humanização do mundo pelo trabalho, dissolvendo a relação de exterioridade que o trabalho mantinha entre o sujeito e as coisas. E do momento em que o uso servil dos elementos do mundo fez um objeto-coisa daquilo que, originariamente, seria da mesma natureza que o sujeito, o sacrifício destrói este objeto enquanto utensílio para restaurar a sua relação original de participação ${ }^{10}$.

O princípio do sacrifício é portanto a destruição, mas ainda que ele possa ir à destruição completa, precisa Bataille, não se deve reduzi-lo a uma simples operação de aniquilamento ${ }^{11}$. É somente o objeto-coisa que o sacrifício quer destruir na vítima, arrancando-a do mundo da utilidade para entregá-la ao mundo do capricho ininteligível. O objeto do sacrifício somente passa para a intimidade do mundo imanente ao deixar de ser separado, como então o era, na subordinação do instrumento ao trabalho. Sua destruição, enquanto utensílio, exprime assim a relação do sujeito para com o mundo da utilidade como uma servidão da qual se tenta escapar. O que se busca é a intimidade perdida da existência soberana à qual responde o sentimento de sagrado, cujo sentido é dado na destruição que visa a consumir sem proveito o que podia restar no encadeamento das obras úteis.

Vale lembrar que íntimo significa, para Bataille, no sentido forte do termo, ausência de individualidade, ausência de separação ${ }^{12}$. Se a intimidade implica, em suas palavras, a violência da destruição, é por não ser compatível com a posição diferenciada do indivíduo separado das coisas no mundo objetivado pelo trabalho. A intimidade opõe à atividade produtora o movimento contagioso de um consumo no qual se nega a individualidade separada. Dali decorre o problema incessantemente colocado pela impossibilidade de ser humano sem ser um objeto-coisa e, por outro lado, escapar aos limites dessa objetividade sem retornar "à l'intimité sans éveil" do sono animal. A esse problema, prossegue Bataille, foi dada "a solução limitada da festa", no sentido em que é bem um desejo de intimidade indiferenciada e destruição que ali explode,

9 BATAILLE. CEuvres Complètes, p. 308.

10 Idem.

11 Ibidem, p. 310.

12 Ibidem, p. 311. Cf. igualmente "La part maudite", op. cit., p. 63. 
embora freado por uma organização social que a contém. O desencadeamento da festa é uma operação de certo modo encadeada, cerceada nos limites de uma realidade à qual a festa se opõe.

Evidencia-se, por conseguinte, tanto na festa quanto nas práticas correlatas do potlach e do sacrifício que Bataille examina minuciosamente, a expressão de uma intimidade negada pela própria organização da sociedade que a promove. Poder-se-ia então, finalmente, localizar, na busca por esta intimidade perdida, a relação, definida por Lacan, do sujeito para com o objeto causa de desejo, homóloga, em certo sentido, ao afã pelo incondicionado do qual bem antes já falara Kant?

Em que pese o forçamento inevitável que subjaz a toda comparação, é possível, ao menos em parte, supor que sim. É sabido, por exemplo, que, se no horizonte da relação ao desejo se atesta o fracasso de toda demanda, é porque pelo desejo se exprime a busca por algo de absoluto que, por se colocar como fim em si, não poderia estar posto em relação na montagem significante. É nesses termos que parece possível pensar o objeto de desejo que se manifesta na dimensão impredicável de das Ding, do projeto freudiano, assim como o objeto que a demanda não alcança, mas em volta do qual se inscreve, para Lacan, o contorno do circuito pulsional ${ }^{13}$. Cumpre salientar, no entanto, que, se é no sentido instrumental do uso que os objetos se deixam apreender nas malhas do significante, o que a relação ao gozo exibe é a natureza da exigência pulsional no sentido da busca por algo que para nada serve ${ }^{14}$. É assim que se coloca, por exemplo, a demanda de amor, na qual a pessoa eleita se delicia com a idéia de ser tomada como fim em si mesma, e sente-se aviltada ao menor sinal de estar sendo usada como meio para algo que lhe é exterior. A metáfora da boca que a si mesma se beija, proposta por Freud para pensar o auto-erotismo, define claramente, por sua vez, o arranjo do circuito pulsional como fim em si mesmo, independentemente de qualquer finalidade que a cultura tenta atribuirlhe.

Disso decorre, a nosso entender, que o aspecto propriamente escandaloso da descoberta freudiana não se deixa explicar simplesmente por uma suposta liberação do dizer sexual. Esse escândalo se deve antes ao fato, que a prática psicanalítica evidencia, de que o sexo não se encontra naturalmente subordinado, como coisa ou objeto instrumentalizado do mundo, a nenhum tipo de finalidade exterior a sua própria satisfação, seja esta a finalidade

13 LACAN, J. Le séminaire livre XI: les quatre concepts fondamentaux de la psychanalyse. Paris: Seuil, 1973, p. $162-169$.

14 LACAN. Le séminaire, livre $X X$ - Encore. Paris: Seuil, 1973, p. 10. 
biológica (reprodução) ou a finalidade cultural (sublimação). Se há algo de específico, com relação ao sexo, que o coloca em posição de escória no interior do mundo instrumentalmente ordenado, esse algo, que a idéia freudiana de uma perversão polimorfa infantil ressalta, é justamente a soberania da satisfação sexual como fim em si, dissociado de toda espécie de vínculo para com as normas instrumentais da cultura.

$\mathrm{Na}$ verdade existe, como nota Bataille, um caráter contagioso na atividade sexual que exclui a possibilidade de sua observação objetiva como coisa neutralizada pela percepção científica. Não se pode ter da atividade sexual uma visão objetiva pela impossibilidade mesma de instrumentalizar essa atividade como meio para um outro fim ${ }^{15}$. É impossível ter do sexo um conhecimento puramente instrumental, posto que não se pode conhecer o sexo sem dele ter alguma espécie de participação íntima, seja ela na forma da excitação que nos atrai, seja ela na forma do sentimento de náusea que nos causa repulsa. Alguém dizia uma vez que o Brasil é um país que não conhece o progresso porque aqui a prostituta se apaixona, o proxeneta tem ciúmes e o traficante se vicia. Seja qual for a validade dessa observação, ela nos permite pensar, ainda que por uma via anedótica, que o que põe a perder a instrumentalização da pulsão é justamente o fracasso de destiná-la ao uso separado do sujeito, pelo qual se exclui a distância requerida pela objetividade científica.

Por outro lado, é bem verdade que existem, como se sabe, tentativas quase sempre desastrosas de objetivar a realidade sexual, num esforço de tratar o sexo como coisa instrumentalizável do mundo. Pelo menos as pessoas de minha geração já devem ter ouvido falar no outrora famoso relatório Shere Hite, que consistia numa tentativa de estabelecer, mediante um inventário de depoimentos levantados pela autora, algum tipo de configuração objetivável dos avatares da sexualidade feminina. Pois são justamente os impasses dessas tentativas de objetivação do sexo que interessam a Bataille, quando ele se debruça sobre o antecessor masculino do relatório Hite, o relatório Kinsey, tanto mais que esses impasses revelam a posição de escória do sexo no interior do mundo ordenado pela instrumentalização do trabalho.

Mas afora os impasses, acima mencionados, desses patéticos esforços de objetivar o sexo através de pseudoprotocolos de observação científica, um outro dado que interessa particularmente a Bataille, no relatório Kinsey, é o fato de não ser a devoção religiosa que inibe a atividade sexual, como se é levado normalmente a supor. $\mathrm{O}$ que inibe a atividade sexual (conforme 
demonstra claramente o relatório) é a devoção ao trabalho, pelo que se observa o maior grau de atividade sexual na escória social (underworld) que desse regime se encontra excluída. Pois se é através do trabalho que o homem ordena o mundo dos objetos-coisa e se reduz, neste mundo, a uma coisa como meio para outras, essa transformação exige precisamente a renúncia da relação ao sexo que para nada serve.

Assim, ao passo que a humanidade, no que ela se define pela relação ao trabalho, tende a sacrificar nossa exuberância sexual, a sexualidade, qualificada de bestial, é o que mais se opõe à redução do homem à condição instrumental de objeto-coisa. Uma vez que o trabalho, por oposição ao sexo, se coloca como condição da consciência instrumental das coisas, a escória social, que não trabalha, e cujo comportamento tende a uma negação da humanidade, tem uma atividade sexual cuja freqüência $(49,4 \%)$ se aproxima da encontrada na natureza, ou seja, da animalidade do antropóide ${ }^{16}$. Mas se essa atividade se opõe ao conjunto dos comportamentos humanizados, é porque pelo trabalho se determina a via da consciência por meio da qual o homem saiu da animalidade e adquiriu a faculdade de discernimento objetivo das coisas. E na medida em que a humanidade se definiu pelo trabalho e pela consciência, ela maldisse a exuberância sexual, fazendo, da relação com o sexo, uma experiência que, embora soberana, estaria para sempre marcada pelo sentimento de asco e vergonha.

Não havendo, portanto, nenhuma propensão natural da pulsão ao arranjo instrumental definido pela cultura, a humanização da criança depende de que se lhe ensine, constata Bataille, "a estranha aberração que é o nojo (dégoût)"17. De modo que, se para Freud o nojo (der Ekel) corresponde ao sintoma de recalcamento de uma antiga zona erógena, conforme ele comenta, a propósito de Dora ${ }^{18}$, é na medida em que o que destina o arranjo do circuito pulsional à finalidade exterior definida pela cultura vem a ser o mesmo fator que gera, na percepção do sujeito, o sentimento de asco face a um objeto que outrora fora investido libidinalmente. Tanto o asco como o sentimento de vergonha que lhe corresponde vêm funcionar, explicita Freud, à maneira de diques (gleichwie Damme) destinados a represar a libido, forçando o sujeito a interromper seu curso rumo a um determinado objeto para o qual ela então fluía ${ }^{19}$. O asco somente se manifesta porquanto persiste, enlaçada a esse objeto, uma quota de

\footnotetext{
16 BATAILLE. Étude I: Kinsey, la pègre et le travail. In: L'Érotisme. Paris: Minuit, 1957, p. 169.

17 Ibidem, p. 66.

18 FREUD, S. Bruchstück einer Hysterie-Analyse. (1905 [1901]). In: Gesammelte Werke [G.W.]. Frankfurt/ Main: Fischer Verlag, 1999, t. V., p. 188-189.

19 FREUD. Drei Abhandlung zur Sexualtheorie. (1905), op. cit., p. 78-79.
} 
participação libidinal que faz com que este ainda se encontre confundido com o sujeito. Para usar finalmente a terminologia de Bataille, pode-se dizer que sentimos asco diante daquilo com relação ao qual mantemos uma espécie de participação íntima que, por persistir, contraria as exigências que nos impõe a cultura de nos desfazer dessa participação.

Há por conseguinte, nessa participação íntima que resiste a ser desfeita, um fator de viscosidade, inerente à libido, contra a qual o sujeito reage através dos sentimentos de asco ou de nojo. Não é por esse motivo casual que encontramos, sob a pluma de Freud, em suas considerações sobre a análise interminável, a surpreendente expressão Klebrigkeit der Libido ${ }^{20}$ (viscosidade da libido). E muito embora esse termo de viscosidade venha evocar, na visão de um Laplanche, a representação freudiana da libido como uma corrente líquida que flui ${ }^{21}$, o que na verdade está ali em questão é menos a representação líquida de uma libido que escorre do que a dificuldade experimentada pelo sujeito de se lavar dela, ou seja, de abandonar esse vínculo de participação íntima para com o objeto que a sexualidade comporta. É como se houvesse um resíduo de adesão libidinal pelo qual o objeto, que resiste a sua transformação utilitária, nos convoca à participação íntima que deveria se interromper com essa transformação. A experiência do asco seria, por sua vez, a reação subjetiva ao elemento viscoso que convoca o sujeito a interromper o encadeamento indefinido das coisas em seu projeto de transformação instrumental do mundo como realidade utilitária, trazendo-o de volta ao vínculo da participação íntima.

A idéia de uma viscosidade inerente à libido diz, portanto, respeito à relação pulsional do sujeito ao desejo, a qual resiste a ser encadeada a uma finalidade externa. Se quisermos então explorar o sentido, por assim dizer, metapsicológico, dessa relação entre o asco e a viscosidade, cujo exemplo seria o caso, mencionado por Freud, da repulsa infantil pela nata, valeria a pena recorrer a um estudo pouco comentado, sobre esse tema, do célebre autor de $A$ náusea, o qual propõe uma verdadeira analítica do viscoso ao final do último capítulo de $O$ Ser e o Nada.

Antes, porém, de resumir a análise de Jean-Paul Sartre acerca da qualidade específica do viscoso, no ponto que ora interessa, cabe explicitar previamente o modo pelo qual ele entende a apreensão da qualidade em geral. A maneira pela qual, segundo Sartre, a qualidade de um objeto é percebida, concerne à apropriação que desse objeto se faz: a qualidade é um efeito da conversão do 
objeto, enquanto puro ser em si, ao para si da consciência, que o nega, na medida em que o submete à percepção por meio da qual ela dele se apropria. A conversão do em si ao para si é, no dizer de Sartre, o que funda a apropriação do objeto como aquilo que existe no mundo conforme o projeto que o sujeito se dá ao realizar sua apreensão. Mas a qualidade do objeto não se reduz, ele adverte, a um simples modo de projeção do sujeito sobre a coisa que ele nega em sua apropriação, como se a cor verde fosse apenas um modo subjetivo de apreensão do limão ${ }^{22}$. A resistência que o objeto opõe a meu esforço em dele me apropriar produz também em mim a impressão de sua qualidade, e é nesse sentido que Sartre propõe analisar a qualidade do viscoso.

Eu só posso qualificar por comparação, escreve Sartre, uma série de objetos como viscosos (um sorriso, uma atitude, um sentimento, uma pessoa), se antes tiver do viscoso uma intuição original ${ }^{23}$. Mas se o sentimento de viscosidade deve então ser pensado com relação ao projeto do ser no mundo, vale lembrar uma vez mais que esse projeto, pelo qual o homem humaniza o mundo através do trabalho, equivale, como se viu, ao plano de sua apropriação instrumental. A apropriação negadora de que fala Sartre aqui significa, para retornar a Bataille, tratar o elemento do mundo como utensílio separado do sujeito, ou seja, como meio para outro fim, fazendo cessar a sua relação original de participação. Se o surgimento do para si ao ser é, como se viu, apropriativo, o viscoso percebido nada mais seria, por sua vez, do que o viscoso a possuir, no sentido em que o que me une ao viscoso é que eu projeto ser o fundamento de seu ser para dele apropriar-me ${ }^{24}$. A qualidade de viscoso será portanto semelhante aos vários encontros enquanto marcados pelo projeto de apropriação.

Mas é justamente no quadro deste projeto apropriativo, expõe luminosamente Sartre, que o visco então se revela e desenvolve sua viscosidade. $\mathrm{O}$ viscoso responde a esse projeto com seu ser, com sua materialidade própria, pela maneira particular que ele tem de fisgar aquele a quem ele se dá, como se a viscosidade, em seu contato, fosse o sentido de ser, do ser em si, que cobra uma intimidade de quem pensa dele poder se apropriar na exterioridade neutra do uso instrumental. Assim, muito embora Sartre recuse, em todos os termos, qualquer tipo de adesão ao pensamento batailleano, não há como não reconhecer, em sua análise do viscoso, o elemento soberano, visado por Bataille, impossível de ser captado na dimensão puramente instrumental de coisa útil, por exigir um vínculo de participação íntima que põe a perder o projeto de sua

22 SARTRE, J.-P. L'Être et le Néant. Paris: Gallimard, 1943, p. 649.

23 Ibidem, p. 651 et seq.

24 Ibidem, p. 652. 
apropriação $0^{25}$. O elemento viscoso é um ser que se pode possuir (ou do qual se pode apropriar), mas que, ao mesmo tempo, não se possui jamais, posto que ele rola sobre nós e a nós se une quando dele queremos nos livrar. O viscoso tem, para dizer como Sartre, "uma instabilidade fixa que desencoraja sua possessão" 26 . Ele nos escapa como a água, mas sem que se possa apropriar de sua propriedade de escapar-se (para se lavar, por exemplo), já que ele igualmente se nega como fuga, colando-se ao corpo do qual parece escapar. Sua fuga líquida é quase uma permanência sólida que se põe a perder ao mesmo tempo que não nos abandona.

Se a atividade humana é pois uma mediação negadora, em seu projeto apropriativo do elemento do mundo, há no viscoso uma resistência que se recusa a se aniquilar em seu ser, ao mesmo tempo que um amolecimento que seria um aniquilamento a meio caminho ${ }^{27}$. O viscoso é compressível, dá a impressão que se pode possuí-lo, mas, no momento em que creio possuí-lo, é ele que me possui. Ali está seu caráter essencial: sua moleza faz ventosa. Ele difere do objeto sólido que pode ser largado, quando eu quiser, e cuja inércia simboliza a potência do para si que absorve o em si. Se a possessão afirma a primazia do para si na composição do em si para si, o viscoso inverte os termos: o para si, que, em princípio, se apropria, se vê subitamente comprometido pelo em si que a ele se prende. Eu quero largá-lo, mas o viscoso se adere a mim. Ele me aspira, cobra de mim uma participação. Ele é, conforme descreve Sartre, uma atividade mole e salivante de aspiração, que vive entre meus dedos e que sinto como vertigem: ele me atrai como o fundo de um precipício ${ }^{28}$.

Disso deriva, prossegue Sartre, uma espécie de fascinação tátil pelo viscoso que me domina no processo de sua apropriação; eu não posso mais detê-lo, ele continua, malgrado eu mesmo. Se é, pois, por um lado, com a "docilidade suprema" do ser possuído que ele se dá, mesmo quando não mais o queremos, por outro lado, o que se realiza, sob esta docilidade, é uma "apropriação dissimulada do possuidor pelo possuído". O símbolo, que ali se destaca, é o mesmo que se desdobra nos temas das possessões venenosas ${ }^{29}$ : é possível que o em si absorva o para si, atraindo-o para sua contingência imanente, sem

\footnotetext{
25 Veja-se, a propósito da posição de Sartre com relação a Bataille, a implacável crítica intitulada "Un nouveau mystique". (In: SARTRE, J.-P. Situations I. Paris: Gallimard, 1976, p. 133-774). Vale notar (p. 157 passim) o quanto a recusa, por parte de Bataille, da dimensão diacrônica do projeto é intolerável à visão historicista e fenomenológica de Jean-Paul Sartre.

26 Ibidem, p. 654.

27 Idem.

28 Ibidem, p. 654-656.

29 Ibidem, p. 655.
} 
finalidade instrumental. Sua armadilha é uma fluidez que me retém, que me convida a apropriá-lo (semelhante à fluidez do líquido e à inércia do sólido), e quando percebo sua real natureza é demasiado tarde: é ele que me fisga. $\mathrm{O}$ viscoso é portanto a revanche do em si que se opõe a seu uso: ele é o que resta do elemento do mundo de que eu acreditava poder dispor sem dele participar, com vista a uma finalidade exterior, na forma do utensílio. Sua sucção esboça a intimidade da participação, restabelecendo uma continuidade de sua substância para comigo mesmo. Por isso existe, na relação com o viscoso, o tormento da metamorfose em que me arrisco a perder a identidade que dele me separa, ao diluir-me em sua viscosidade ${ }^{30}$.

Se Freud vê então, na viscosidade da libido, um elemento não analisável, impossível de modificar, chegando a concebê-la ao modo de um fator constitucional constante que se agrava com o envelhecimento, pode-se arriscar dizer que pela viscosidade se define a dimensão não utilizável que a libido manifesta em sua experiência. Dela deriva a permanência inevitável, em todo e qualquer tratamento, de um resíduo sintomático que nunca se logra dissipar, em que pesem os melhores e mais bem intencionados esforços terapêuticos. Pois essa falta de êxito não se deve a uma insuficiência terapêutica da prática psicanalítica que um aprimoramento técnico poderia sanar; o que está em questão é a composição libidinal do sintoma que não pode ser orientada para o tratamento. O que se revela, nessa aderência do sujeito ao sintoma intratável, é a própria viscosidade da libido cuja presença se atesta, aos olhos de Freud, na forma de uma energia não utilizável, comparável ao fator de entropia no sistema físico $^{31}$. Isso nos obriga a considerá-la em sua condição soberana, conforme descreve Bataille, a propósito do que para nada serve, e que portanto se opõe, no caso da experiência analítica, a todo tipo de finalidade terapêutica.

Essa constatação não deve, contudo, nos conduzir a uma atitude niilista quanto aos efeitos que se pode esperar da psicanálise. Se há verdade em dizer, segundo o provérbio, que o que não tem remédio remediado está, caberia antes conceber essa dimensão irremediável do sintoma como uma solução possível para aquilo que não tem tratamento. Assim, do mesmo modo que, para Bataille, o grande problema da condição humana concerne ao desejo, manifesto pelo sujeito, de escapar à condição instrumental de objeto-coisa que o determina, no mundo humanizado pelo trabalho, sem todavia retornar à intimidade indiferenciada que ele mantinha com o mundo, em sua condição animal, o drama ao qual responde o sintoma diz respeito, por sua vez, à necessidade em

30 BATAILLE. Un nouveau mystique. In: SARTRE. Situations, p. 656.

31 FREUD. Die endliche und die unendliche Analyse. (1937), G. W., t. XVI, p. 87. 
que se encontra o sujeito de conciliar a satisfação libidinal, a princípio soberana, ao uso que a cultura exige que dela se faça. Em Bataille, conforme se viu acima, a esse problema da busca pela intimidade no mundo instrumentalizado foi dada a solução da festa, mediante a qual a organização social contém o desejo da intimidade indiferenciada dentro de limites determinados no calendário dos dias úteis. A organização social da festa seria uma tentativa de produzir o encadeamento do desencadeado, cerceando-o nas fronteiras de uma realidade da qual ele é a negação.

O que dizer então do sintoma psicanalítico, que se por um lado se deixa decifrar como mensagem, no campo do significante, ao mesmo tempo mantém a opacidade de um gozo autista que o recurso à linguagem não logra modificar? Não caberia conceber a solução sintomática, desde a perspectiva psicanalítica, como uma tentativa homóloga de encadear o desencadeado? Não seria, finalmente, o sintoma, em seu resíduo intratável, a única possibilidade que resta ao sujeito de pôr em relação, na cadeia significante, o que ali não é relacionável, qual seja, o modo de satisfação ao qual ele se adere mas que o discurso que o determina não autoriza significar? 